\title{
Effect of Vegetation Cover and Shading on Thermal and Visual Comfort in Institutional Campus Outdoor Spaces in India
}

\author{
Satpal, Aastha Kalia
}

\begin{abstract}
This paper investigates the phenomenon of Urban Heat Island (UHI) in open spaces that when combined creates a problem at a city level. This paper will primarily focus on institutional campuses, wherein open spaces play a vital role for each and every user for interaction and other purposes. When architects and urban designers deal with the physical properties of a space, and therefore modify its material, thermal, and lighting characteristics, they influence the social environment as well. The method used in this study is the analysis of secondary data available so far. The aim of the study is to understand the UHI phenomenon in urban public spaces and suggest measures that would help mitigate the same and make it a better space in terms of comfort. It includes off-site measurement of climatic conditions on particular given day and observations of student behavior in the public spaces. The result is obtained by ENVImet software simulation in the case study area of DCRUST university campus in Murthal, Haryana. The study area is located in the North part of India and has composite climate. This paper refers to research results showing the comparison of various cases that can be designed in an urban open space and with the help of simulation it shows the best combination to be used and how that combination changes the open space design by improving thermal comfort. It shows that in composite climate, the strategy of implementing thick and heavy foliage vegetation in combination with the water body (such as artificial ponds, swales, pits etc.) causing evaporative cooling that in return enhances the microclimatic environment and visual comfort for pedestrian walkability, usability of the open space and by acting against the anthropogenic heat.
\end{abstract}

Keywords: Urban Heat Island, ENVI-met, Thermal comfort, Visual effects, and Outdoor space

\section{INTRODUCTION}

$\mathrm{H}$ eat island effect is a multifaceted microclimate phenomenon that mostly hit the tropical cities round the earth. Urban heat island (UHI) may occur as a result of unsuitable building surfaces or outdoor climatically unresponsive open areas for different climates (Wang \& Shu, 2020). The physical properties of outdoor spaces may affect due to design of buildings, orientation, exterior building materials and temperature of the region.

Manuscript received on June 07, 2021

Revised Manuscript received on June 11, 2021.

Manuscript published on July 30, 2021.

* Correspondence Author

Dr. Satpal*, Deenbandhu Chhotu Ram University of Science and Technology, Murthal Sonepat (Haryana), India. Email: satpal.arch@dcrustm.or

Ar. Aastha Kalia, Deenbandhu Chhotu Ram University of Science and Technology, Murthal Sonepat (Haryana), India. Email: aastha.kalia@gmail.com

(C) The Authors. Published by Blue Eyes Intelligence Engineering and Sciences Publication (BEIESP). This is an open access article under the CC BY-NC-ND license (http://creativecommons.org/licenses/by-nc-nd/4.0/)
In composite climate where summers are pre-dominant round the year and get extreme, the usages of outdoor areas are frequently hindered due to thermal discomfort. But certain alterations to the surroundings can improve the outdoor thermal comfort and make the spaces possibly delightful for students to use and enjoy. Potential mitigation strategies, focusing primarily on increasing vegetation or use of water bodies and more extensive use of shading, are also described. The predicted rise in air temperatures due to climate change worsens the urban areas by creating urban heat island effect, which becomes obvious (LIANG, 2015).

Campus outdoor spaces are most important for the social life of public due to their capacity to serve as meeting spaces and be conducive to interactions among the people. Moreover, outdoor spaces play a large role to define the quality of life experienced by peoples. For this reason, it is essential that outdoor public spaces be attractive and comfortable, as they are places where collective values are built" (Louafi, Abdou, \& Reiter, 2017). The usages of outdoor areas are frequently hindered due to thermal discomfort, but certain alterations to the surroundings can improve the outdoor thermal comfort and make the spaces possibly delightful for users. Potential mitigation strategies, focusing primarily on increasing vegetation or use of water bodies and more extensive use of shading, are described in this study. The example of use of water bodies in open spaces to promote evaporative cooling and cool breeze ventilation is as below.

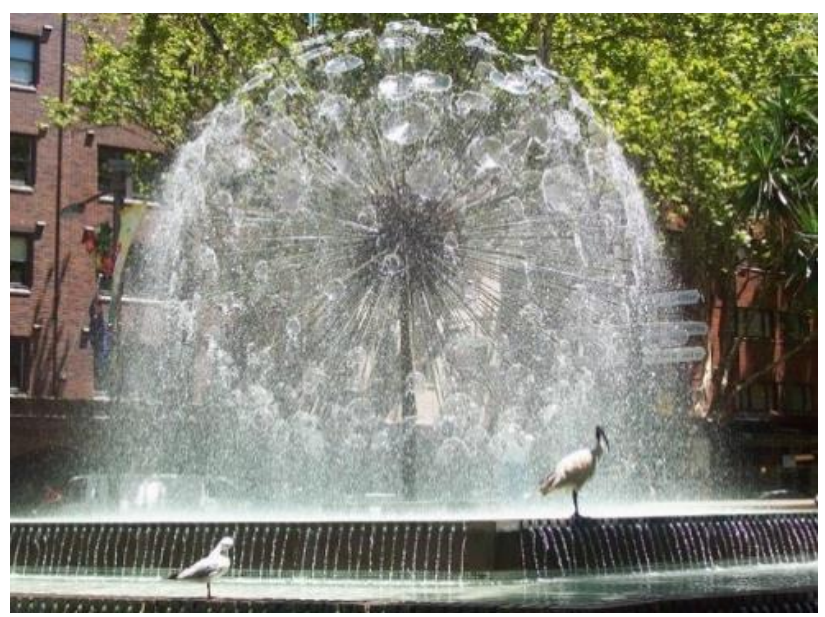

Figure 1: Delmar Gardens Fountains (Williams, 1961)

Published By:
Blue Eyes Intelligence Engineering and Sciences Publication (C) Copyright: All rights reserved.

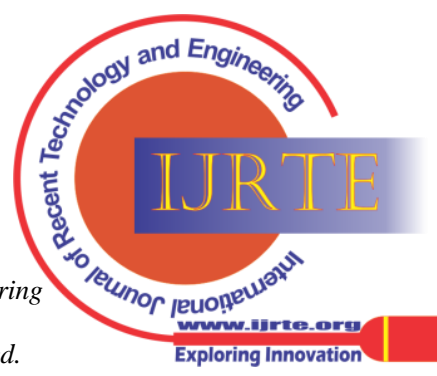




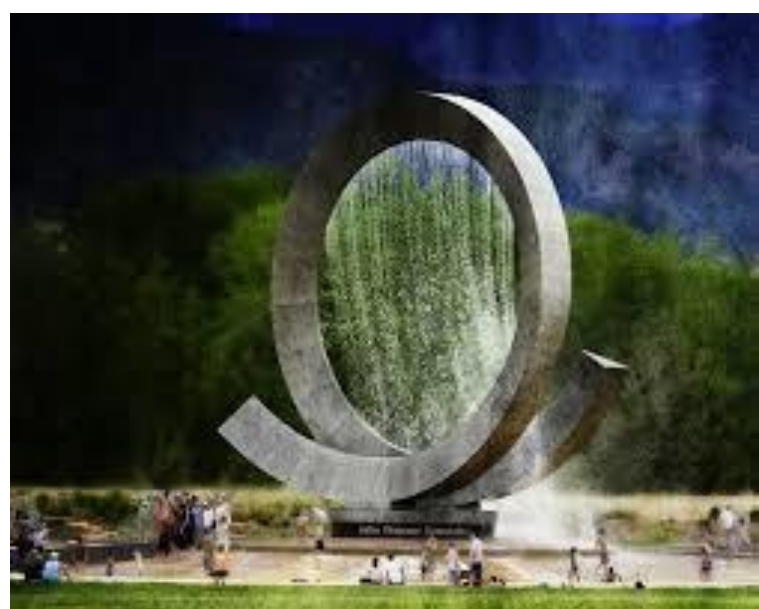

Figure 2: Julie Penrose Fountain (Burgess, 2007)

The physical properties of a space, such as materiality, temperature, or light, can enhance or inhibit people from using and enjoying it. When architects and urban designers deal with the physical properties of a space, and therefore modify its material, thermal, and lighting characteristics, they influence the social environment as well (Guayo \& Yannas, 2014). This research paper primarily focuses on institutional campuses, wherein open spaces play a vital role for each and every user.

The research paper aims to compare the performances of various strategies like shading, use of vegetation (Greening), and use of water bodies that tends to enhance microclimate of a particular site. The performances of these strategies have been calculated by the data collection from secondary sources and by simulating the effects of the same on basic models in ENVI-met software. "The ENVI-met model is one of the most widely employed dynamic simulation tools" (S.Tsoka, A.Tsikaloudaki, \& T.Theodosiou, 2018). The readings of difference in temperatures before and after applying strategies is noted and analyzed. Also the predicted rise in air temperatures due to climate change worsens the open areas by creating heat island effect, which becomes obvious. This study refers to research results showing how changes to open space design can improve thermal comfort and are derived in terms of suggestions of efficient practices for designing an outdoor space to be comfortable round the year in composite climate. It includes off-site measurement of climatic conditions on particular given day and observations of student behavior in the public spaces.

\section{BACKGROUND}

Today climate change (macroclimatic phenomenon) has led to a massive increment in the ambient temperature and heat island effect that has increased the discomfort conditions at the micro level (open spaces) too. Strategies for coping up with this increment in heat are described in the study.

This study will focus on the comparison between the vegetation, use of water body and shading on the outdoors that will enhance the microclimate and will eventually be the strategic solution to the cooling up of outdoors and reducing the occurring of heat island effect. Since heat gain is major problem in tropical cities so in order to address the same in context of India we have chosen composite climate and the New Delhi as my case study. ENVI-met software is used to simulate climates in urban environments and assess the effects of atmosphere, vegetation, architecture and materials (Envi-met, 2018). Also the open spaces play a vital role in university campuses so the scope is limited to the same.

\section{SITE DATA}

LAYOUT PLAN FOR DEENBANDHU CHHOTU RAM UNIVERSITY OF SCIENCES \& TECHNOLOGY AT MURTHAL DISTT. SONEPAT

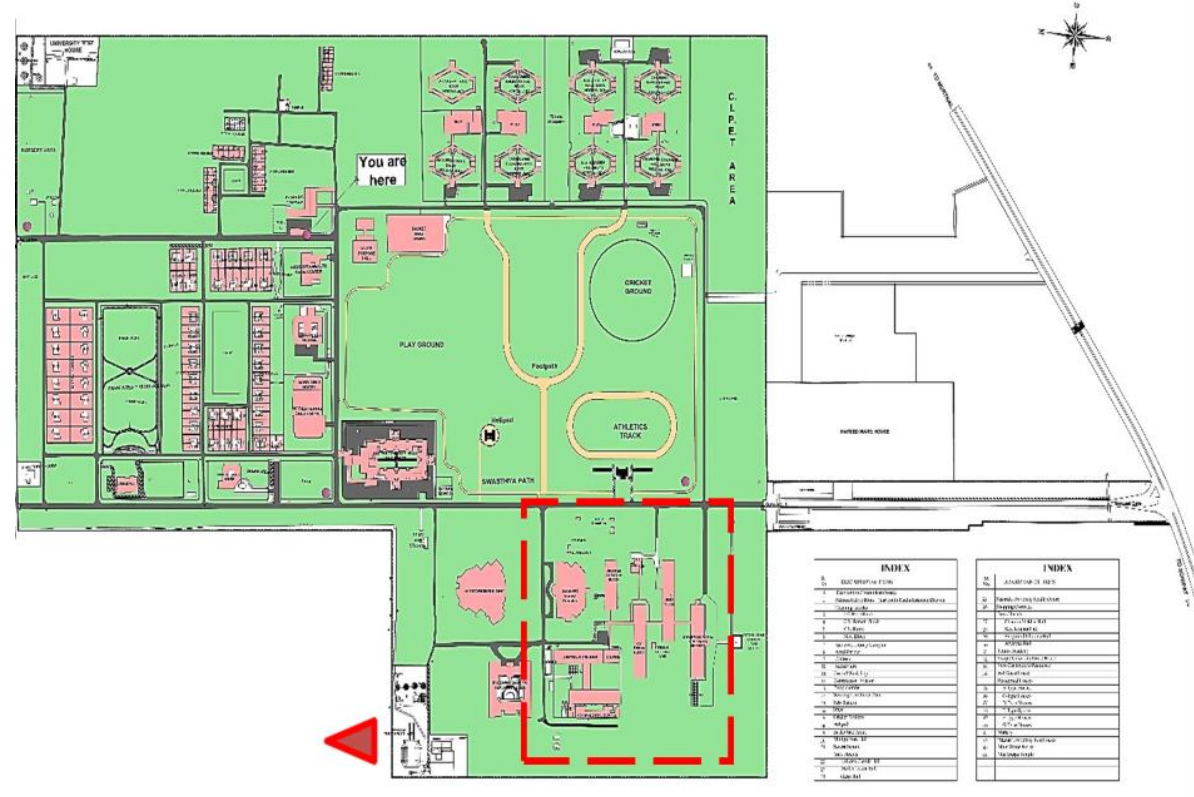

Figure 3: Layout Plan of Deenbandhu Chhotu Ram University of Science and technology, Murthal

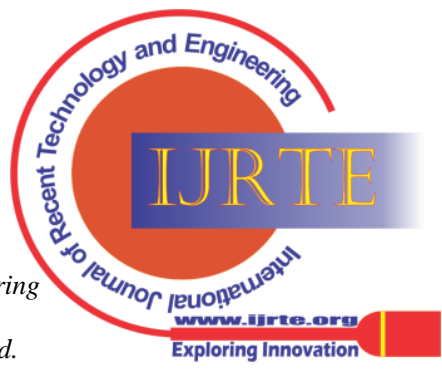


Table 1: Simulation data of different cases.

Study area is located at university campus of Deenbandhu Chhotu Ram University of Science and Technology Murthal, Sonepat (Haryana), India. The site latitude is $29.0272^{\circ} \mathrm{N}$ and longitude is $77.0621^{\circ} \mathrm{E}$ (Mapia, 2021). It is about $45 \mathrm{kms}$ away from New Delhi on National Highway-44. There are no such contours on the site, it is a flat land. Sandy soil is found in maximum areas and native trees are keekar, neem, ashoka and ficus. University campus has a lot of trees but cannot be remarked as lush green campus. The climate of the area is composite and New Delhi weather station data is referred in this study.

The site is an educational institute and academic zone (surrounding open spaces are used maximum in the daytime: 9am to 5pm); Identified zones that are used the most according to the survey from the university students. The open spaces of the academic zone are used in both summers and winters, in the daytime. Open spaces act as an informal interaction spaces allow recreational and visual activity for students, teachers.

\section{DATA ANALYSIS}

This study is based on microclimate simulations using the software ENVI-met, validated with air temperature and solar radiation data taken from New Delhi weather data (Salvati \& Kolokotroni, 2020). In this study, the layout of the campus area was imported from AutoCAD software. "The ENVI-met system allows for the analysis of design impacts on the local environment, the specification of vegetation on walls or roofs in any thinkable configuration to help mitigate factors such as urban heat island" (Envimet, 2018). On the basis of manual survey, the zone marked in the master plan of DCRUST was maximum use profiles, including teaching, non-teaching and students. It was the most used outdoor space for the campus. Thereafter, the model was created on ENVI-met and simulated for the hottest day and time for the composite climate.

Different passive strategies and combinations of the same options were used as cases for simulation. These cases included the following:

a. Existing case

b. With no vegetation, water body or shading

c. With extensive vegetation and shading

d. With water body

e. With water and body and extensive vegetation

The following parameters are used for analysis and development of base case

The case for simulation done is as follows:

1. Month: June( SUMMER)

2. Day: Summer Solstice (21 JUNE)

Time Taken: 3pm- 4pm (maximum air temperature recorded as per energy plus)-41.6 degree Celsius microclimate and thermal comfort implications of changing the water body and vegetation scenario in the case study area. "The impact of materials reflectivity of facades and roads on outdoor thermal comfort is assessed in terms of hourly PET changes under heatwave conditions" (Salvati \& Kolokotroni, 2020). In this study five scenarios were tested to prepare the model. The simulation data on ENVI-met software represent the following results and is shown in the table 1. ground plane and building materials, and the usage of

An ENVI-met model of the area was built to simulate the

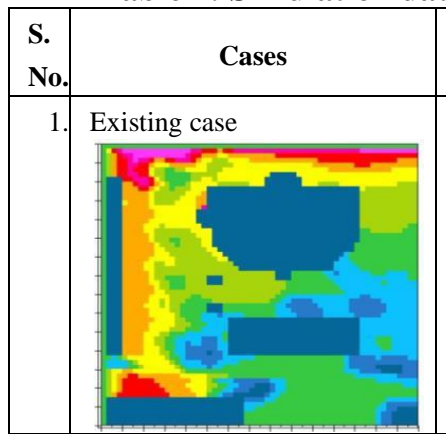

2. With no vegetation, water body or shading
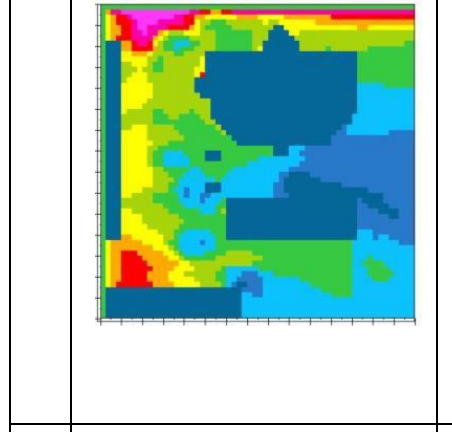

3. With extensive vegetation and shading

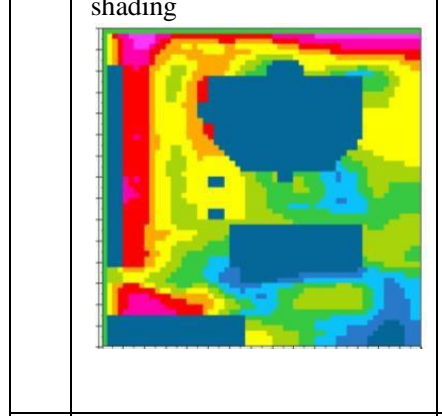

4. With water body
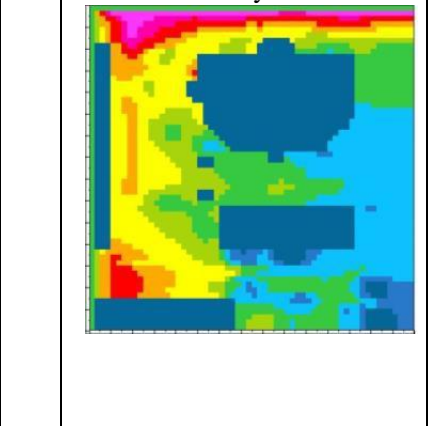

5. With water and body and extensive vegetation

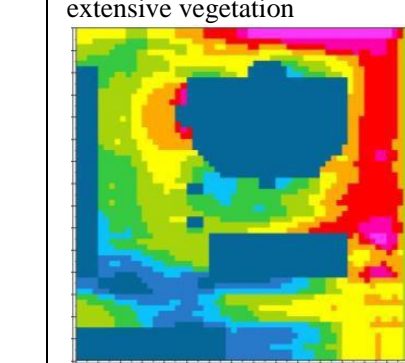

Result (all readings in ${ }^{\circ} \mathrm{C}$ )

BASE CASE(WEATHER

DATA): $41^{\circ} \mathrm{C}$

EXISTING:

ZONE 1: 37.72

ZONE 2: 37.86

REDUCTION in temp.

ZONE 1: 3.28 decrease from base

ZONE 2: 3.14 decrease from base

\section{TEMP. RECORDED}

ZONE 1: 38.02

ZONE 2: 38.15

REDUCTION in temp.

ZONE 1: 0.3 increased from

existing

ZONE 2: 0.29 increased from existing

REDUCTION in temp. from BC

ZONE 1: 2.98 decreased from existing

ZONE 2: 2.85 decreased from existing

TEMP. RECORDED

ZONE 1: 36.37

ZONE 2: 36.44

REDUCTION in temp.

ZONE 1: 1.35 decreased from

existing

ZONE 2: 1.44 decreased from existing REDUCTION in temp. from $B C$

ZONE 1: 4.63 decreased from existing

ZONE 2: 4.56 decreased from existing

\section{TEMP. RECORDED}

ZONE 1: 38.21

ZONE 2: 38.14

REDUCTION in temp.

ZONE 1: 0.49 increased from

existing

ZONE 2: 0.28 increased from existing REDUCTION in temp.

From BC. ZONE 1: 2.79

decreased from existing

ZONE 2: 2.86 decreased from existing

\section{TEMP. RECORDED}

ZONE 1: 36.37

ZONE 2: 36.44

REDUCTION in temp.

ZONE 1: 1.35 decreased from existing ZONE 2: 1.42decreased from existing REDUCTION in temp. from BC

ZONE 1: 4.63 decreased from existing

ZONE 2: 4.56 decreased from existing
Blue Eyes Intelligence Engineering and Sciences Publication (C) Copyright: All rights reserved.

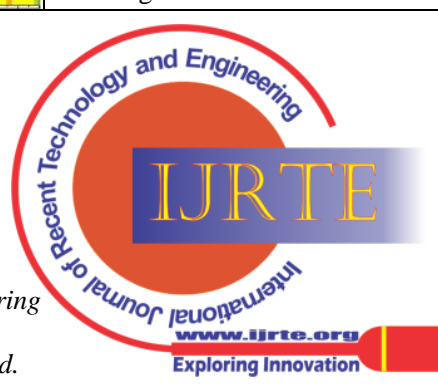


Based upon these cases, simulation was run through ENVI-met, on the harshest and hottest day of the climatic zone to identify the temperature difference before and after the case implementation on the outdoor space. The best option appeared to be the maximum vegetation and water body, as can be implied from the table above, that shows the results of ENVI-met. It showed the maximum air temperature difference.

According to results, the existing case is pretty much good for the surroundings but the case with extensive vegetation and other with the combination of both vegetation and water body shows significant reduction in air temperature, hence making it more pleasant. The existing case shows that there is a reduction of 3.28 degree from the recorded climatic data's air temperature that is 41 degree Celsius.

As it is observed clearly that there is a difference of 0.01 degree Celsius in CASE 3 and CASE 5 so by this study it is concluded that the best solution for enhancing microclimate happens to be the combination of both vegetation and water body and vegetation alone too. Applying these two in the surroundings will ensure improvement in outdoor thermal comfort and will also fight heat island to form by acting against the anthropogenic heat. To improve the thermal comfort in the study area, it is recommended to do the combination of vegetation and water bodies to maximize the shading effect and thermal comfort at outdoor.

\section{CONCLUSION}

This study provides the complex relationship between the outdoor thermal comfort condition and urban variables. It has proved that urban design elements can improve the urban micro-climate. Increasing the vegetations and water body will have positive impact. The research study provides the information on the issues relating to poor outdoor comfort in open spaces particularly of composite climate. This strategy can prove to be beneficial in institutional campuses, as the open space is used for multiple formal and informal events that can lead to strengthen and reinforce the social sustainability of the campus by making it walkable, sustainable, climate responsive and at the same time, make it more user-friendly.

Further, this study would also be a review on strategies that promote thermal comfort outside the building. This can be achieved through efficient passive site planning, architectural interventions or alterations. This study would be beneficial to the architects, researchers and urban designers who are and will provide the necessary information on the different shortcomings related to microclimate like heat island effect. It is expected to highlight the awareness of the heat island effect and performances of various strategies like heavy vegetation, water bodies and shading. To the future researchers, this study can provide baseline information on the recent performance status according to composite climate viz-a-viz open spaces.

\section{REFERENCES}

1. Burgess, D. B. (2007). Julie Penrose Fountain. Retrieved Jan 20 2021, from Hydro Dramatics: http://hydrodramatics.com/americathe-beautiful

2. Envi-met. (2018, May). ENVI_MET Decoding Urban Nature. Retrieved from https://www.envi-met.com/.

3. Guayo, P. M., \& Yannas, S. (2014). Improving Outdoor Urban
Environments:Three Case Studies in Spain. 30th International PLEA Conference (pp. 1-8). Ahmedabad: CEPT University.

4. LIANG, T. C. (2015). Effect Of Rooftop Greenery on Outdoor Mean Radiant Temperature in the Tropical Urban Environment. Singapore: ScholarBank@NUS.

5. Louafi, S., Abdou, S., \& Reiter, a. S. (2017). Effect of vegetation cover on thermal and visual comfort of pedestrians in urban spaces in hot and dry climate. Nature \& Technology , 30-41.

6. Mapia, I. (2021, May). https://indiamapia.com/Sonipat/Murthal.html.

7. S.Tsoka, A.Tsikaloudaki, \& T.Theodosiou. (2018). Analyzing the ENVI-met microclimate model's performance and assessing cool materials and urban vegetation applications-A review. Sustainable Cities and Society, 55-76.

8. Salvati, A., \& Kolokotroni, M. (2020). Impact of urban albedo on microclimate and thermal comfort over a heat wave event in London. Windsor 2020 Resilient Comfort, (pp. 574-586). London.

9. Wang, L. (., \& Shu, C. (2020). Assessment of the Effects of Urban Heat Island on Buildings. In: Enteria N., Santamouris M., Eicker U. (eds) Urban Heat Island (UHI) Mitigation. Advances in 21st Century Human Settlements. . Montreal, Canada: Springer, Singapore.

10. Williams, J. (1961). El Alamein Memorial Fountain. Retrieved December 20, 2020, from City of Sydney: https://www.cityartsydney.com.au/artwork/el-alamein-fountain/

\section{AUTHORS PROFILE}

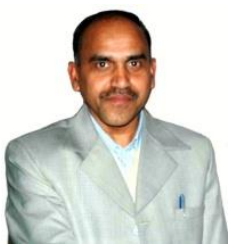

Dr. Satpal, an Architecture graduate in 1996 from Chhotu Ram State College of Engineering, Murthal affiliated with GJU Hisar, Master of Town Planning in 2012 from Institute of Town Planners, India a New Delhi and Doctor of Philosophy in Architecture in 2021 from DCRUST Murthal, Sonipat Haryana. He has more than $10+y r s$ of professional and $15^{+}$ year of teaching experience. He is currently working as an Associate Professor in the Department of Architecture at DCRUST Murthal, Sonipat Haryana. His current research interest includes Transit Oriented Development, walkability, Urban Transit Planning and sustainable development.

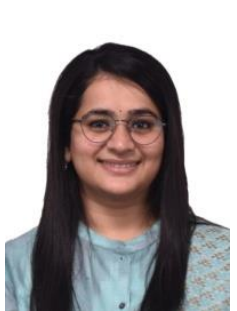

Architect Aastha Kalia, is an academician and an environmentalist who has graduated from DCRUST, Murthal, and holds a Masters in Sustainable Architecture from the same University. She is trained under the Sustainable Solutions Group of AECOM India - a Multi-National Company and worked for achieving GRIHA ratings on pioneer projects. She is a GRIHA Certified Professional. She has also worked with Kothari Associates on several projects. As an academician, she has her inclination towards design thinking, creating better processes, and innovative methods to enrich the classroom experience for students.

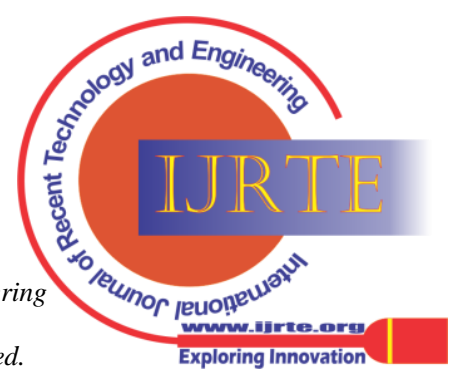

